\title{
SCOPE OF PRACTICE FOR REHABILITATION COUNSELING
}

\section{Assumptions}

- The Scope of Practice Statement identifies knowledge and skills required for the provision of effective rehabilitation counseling services to persons with physical, mental, developmental, cognitive, and emotional disabilities as embodied in the standards of the profession's credentialing organizations.

- Several rehabilitation disciplines and related processes (e.g., vocational evaluation, job development and job placement, work adjustment, case management) are tied to the central field of rehabilitation counseling. The field of rehabilitation counseling is a specialty within the rehabilitation profession with counseling at its core, and is differentiated from other related counseling fields.

- The professional scope of rehabilitation counseling practice is also differentiated from an individual scope of practice, which may overlap, but is more specialized than the professional scope. An individual scope of practice is based on one's own knowledge of the abilities and skills that have been gained through a program of education and professional experience. A person is ethically bound to limit his/her practice to that individual scope of practice.

\section{Underlying Values}

- Facilitation of independence, integration, and inclusion of people with disabilities in employment and the community.

- Belief in the dignity and worth of all people.

- Commitment to a sense of equal justice based on a model of accommodation to provide and equalize the opportunities to participate in all rights and privileges available to all people; and a commitment to supporting persons with disabilities in advocacy activities to achieve this status and empower themselves.

a Emphasis on the holistic nature of human function which is procedurally facilitated by the utilization of such techniques as:

1. interdisciplinary teamwork.

2. counseling to assist in maintaining a holistic perspective.

3. a commitment to considering individuals within the context of their family systems and communities.

․ Recognition of the importance of focusing on the assets of the person.

a Commitment to models of service delivery that emphasize integrated, comprehensive services which are mutually planned by the consumer and the rehabilitation counselor.

\section{Scope of Practice Statement}

Rehabilitation counseling is a systematic process which assists persons with physical, mental, developmental, cognitive, and emotional disabilities to achieve their personal, career, and independent living goals in the most integrated setting possible through the application of the counseling process. The counseling process involves communication, goal setting, and beneficial growth or change through self-advocacy, psychological, vocational, social, and behavioral interventions. The specific techniques and modalities utilized within this rehabilitation counseling process may include, but are not limited to:

- assessment and appraisal;

- diagnosis and treatment planning;

- career (vocational) counseling;

口 individual and group counseling treatment interventions focused on facilitating adjustments to the medical and psychosocial impact of disability;

- case management, referral, and service coordination;

a program evaluation and research; 
- interventions to remove environmental, employment, and attitudinal barriers;

- consultation services among multiple parties and regulatory systems;

口 job analysis, job development, and placement services, including assistance with employment and job accommodations; and

u the provision of consultation about and access to rehabilitation technology.

\section{Selected Definitions}

The following definitions are provided to increase the understanding of certain key terms and concepts used in the Scope of Practice Statement for Rehabilitation Counseling.

Appraisal: Selecting, administering, scoring, and interpreting instruments designed to assess an individual's aptitudes, abilities, achievements, interests, personal characteristics, disabilities, and mental, emotional, or behavioral disorders as well as the use of methods and techniques for understanding human behavior in relation to coping with, adapting to, or changing life situations.

Diagnosis and Treatment Planning: Assessing, analyzing, and providing diagnostic descriptions of mental, emotional, or behavioral conditions or disabilities; exploring possible solutions; and developing and implementing a treatment plan for mental, emotional, and psychosocial adjustment or development. Diagnosis and treatment planning shall not be construed to permit the performance of any act which rehabilitation counselors are not educated and trained to perform.

Counseling Treatment Intervention: The application of cognitive, affective, behavioral, and systemic counseling strategies which include developmental, wellness, pathologic, and multicultural principles of human behavior. Such interventions are specifically implemented in the context of a professional counseling relationship and may include, but are not limited to: appraisal; individual, group, marriage, and family counseling and psychotherapy; the diagnostic description and treatment of persons with mental, emotional, and behavioral disorders or disabilities; guidance and consulting to facilitate normal growth and development, including educational and career development; the utilization of functional assessments and career counseling for persons requesting assistance in adjusting to a disability or handicapping condition; referrals; consulting; and research.

Referral: Evaluating and identifying the needs of a client to determine the advisability of referrals to other specialists, advising the client of such judgments, and communicating as requested or deemed appropriate to such referral sources.

Case Management: A systematic process merging counseling and managerial concepts and skills through the application of techniques derived from intuitive and researched methods, thereby advancing efficient and effective decision-making for functional control of self, client, setting, and other relevant factors for anchoring a proactive practice. In case management, the counselor's role is focused on interviewing, counseling, planning rehabilitation programs, coordinating services, interacting with significant others, placing clients and following up with them, monitoring progress, and solving problems.

Program Evaluation: The effort to determine what changes occur as a result of a planned program by comparing actual changes (results) with desired changes (stated goals), and by identifying the degree to which the activity (planned program) is responsible for those changes.

Research: A systematic effort to collect, analyze, and interpret quantitative or qualitative data that describe how social characteristics, behavior, emotions, cognition, disabilities, mental disorders, and interpersonal transactions among individuals and organizations interact.

Consultation: The application of scientific principles and procedures in counseling and human development to provide assistance in understanding and solving current or potential problems that the consultee may have in relation to a third party, be it an individual, group, or organization.

\section{RECOMMENDED CITATION}

Commission on Rehabilitation Counselor Certification. (n.d.). Scope of Practice for Rehabilitation Counseling.

Schaumburg, IL: Author. 